\title{
Low-Cost Sensors Calibration for Monitoring Air Quality in the Federal District-Brazil
}

\author{
Erick Frederico Kill Aguiar, Henrique Llacer Roig, Luís Henrique Mancini, \\ Eduardo Neiva Caetano Botelho de Carvalho \\ Institute of Geosciences (IG), University of Brasilia, Brasilia, Brazil \\ Email: erickfkill@gmail.com, roig@unb.br, Imancini@unb.br, duduts86@gmail.com
}

Received 1 February 2015; accepted 15 February 2015; published 25 February 2015

Copyright (C) 2015 by authors and Scientific Research Publishing Inc.

This work is licensed under the Creative Commons Attribution International License (CC BY). http://creativecommons.org/licenses/by/4.0/

\section{(c) (i) Open Access}

\begin{abstract}
Critical situations that cannot be solved by conventional approaches (traditional air quality monitoring networks), have the possibility of being managed quickly by a wide network of portable systems with sensors. The purpose of this research was to calibrate and validate low-cost sensors. Pilot indoor and outdoor areas, in the central area of Brasilia (Brazil's capital city) were

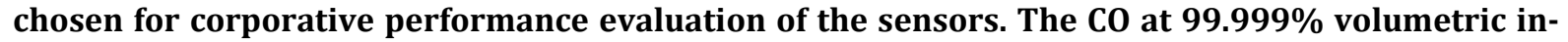
jection method has been used in a gas test box, among two MiCS-5521 (CO/VOC) sensors, one being new and the other one with a short useful life. The number of injections adopted to each volume (from $1 \mathrm{ml}$ to $6 \mathrm{ml}$ ) was 10, rising each sensor's confidence interval mean. A increase of the injected volume ( $\mathrm{ml}$ ) of CO resulted in significant decrease in a resistance (Ohms), as shown by a good inverse relationship on the interaction of these two variables $(r=0.88)$, with good measurement accuracy, when compared to the manufacturer's reference datasheet. Finally, a geospatial management system was built for the pollution data measured by the low-cost sensors.
\end{abstract}

\section{Keywords}

Low-Cost Sensors, Monitoring Air Quality, Calibration of Micro-Sensors MiCS-5521 (CO/VOC), WebGIS

\section{Introduction}

The atmospheric urban pollution is a major concern in modern cities, especially in developing countries [1] [2], where pollutants affect directly human health and cause various respiratory and cardiovascular diseases, when 
there is long term exposure to pollution [3]-[5]. The World Health Organization (WHO) reported that high concentrations of gases and particulates were the cause of 223,000 lung cancer deaths around the world in 2010 [6]. In the last decades, many studies demonstrated positive associations between air pollution and mortality [7]-[9].

In this context, information about pollutant emissions released in urban areas is very important to public health policies for human health and environmental protection [2] [4]. Currently, monitoring is done by static measuring stations (subsequently called base stations) that are operated by official authorities, such as governmental environment organs. This monitoring has high reliability in terms of data generation and it is capable of measuring, with precision, a wide variety of atmospheric pollutants using traditional analytic instruments, like mass spectrophotometers and gas chromatograph. However, the disadvantages of such measuring methodology are its complexity and high maintenance cost [10] [11], for this reason it is not available in many urban centers [8].

Two basic limitations exist in the approach used to control and publish air quality data: First, the spatial resolution sampling is low, making it necessary to use mathematical models to estimate the concentrations of pollutants in not monitored metropolitan areas. Second, pollutants concentration observations do not reflect actual exposure suffered by people, due to spatial heterogeneity in pollutant concentrations and the individual mobility patterns [12].

Measuring protocols and monitoring sensors are extremely new and much research is still needed in order to integrate these technologies and improve environmental information systems. An important point to improve air quality monitoring is sharing of environmental data gathered from different sources (public and private companies), into a real-time system, in order to merge data from different sensor networks [10] [12] [13].

In Sydney, Australia [12], the Project "HazeWatch" involved citizens participation in the management of the pollution they are exposed to, utilizing customized tools, such as micro systems controlled by low-cost sensors, to generate real-time information. The research achieved satisfactory results regarding the understanding of urban air quality, as information about exposure to determined type of pollutant during one's quotidian is presented to the user of the system, characterizing it as a mean of increasing environmental awareness.

In Brazil there are a total of 5570 cities, but only $1.7 \%$ of them have an air pollution monitoring network. Nationally, there are 252 monitoring stations, but not every station monitors all important pollutants [14]. The city which is best monitored in Brazil is São Paulo [15] [16]. This Metropolitan area has a traditional monitoring network (stationary and mobile stations), creating reports on regional situations, which can be accessed on the web, through the institutions portals. The advantage of this type of system is the quality level of the information that can be correlated with several variables, allowing more precise environmental modeling.

On the other hand, regions such as the Federal District (Brazilian Capital) have an inefficient network regarding data generation and monitoring of the local air quality [17]-[19], which opens the opportunity of investments on alternative mobile portable monitoring networks, diminishing the costs invested by the government [20].

Thus the research fits the perspective of generating distributed monitoring systems, if possible with the participation of collaborative networks.

\section{Materials and Methods}

In order to acquire the response to the resistance signals of the micro controlled plate on the experiment, the software used was from MiCS-EK1 kit, manufacturer E2V [21] (Figure 1(a)), that shows the reading of two metal oxide sensor slots, with results in resistance units (KOhms or Ohms). Other two fields make the working temperature of the plate and the humidity reading (factory calibrated sensors). With that, a data logging is generated, which can be defined in the time scale desired by the user. The final data are saved in a CSV (.csv) file.

At the sensors calibration stage, an area from the Geochronology laboratory was used, as well as a CO gas cylinder, the pressure regulator, syringes for the volumetric injections, needles and digital thermometer, detailed below.

The Carbon Monoxide cylinder with volume capacity of $8.5 \mathrm{~m}^{3}$ in the laboratory, possesses concentration of 99.999\% - 5.0 analytical. The removal of CO from the cylinder was made through the outlet of the pressure regulator, where the duct outlet had a silicone cap, which would open the cap to release the gas and then use the needle on the syringe to remove the volume to be used in each measurement. 
For the CO injection, there were used glass hypodermic syringes with $3 \mathrm{ml}, 5 \mathrm{ml}$ and $10 \mathrm{ml}$ volumes and needles measuring $16 \mathrm{G} 1.5(1.60 \mathrm{~mm} \times 40 \mathrm{~mm})$.

The SR \# 3 (Figure 1(b)) is a gas testing box, made by the Japanese industry Figaro [22], with the specifications Power Source: 110X A.C 50/60 Hz; Consumption: 10 W; Dimensions: 235 mm × 180 mm × 210 mm; Effective volume: $5.4 \mathrm{~L}$; and Material: Acrylic.

The sensor used was MiCS-5521 from E2V [21], which is indicated for the detection of gases such as carbon monoxide (CO), hydrocarbons (HC) e volatile organic compounds (VOC). Sensor 1 was never used and sensor 2 was used for a year and a half. According to the producer, the sensor has a two year useful life-time. An experimental micro controlled system (Figure 2(a), Figure 2(b)), was used, developed by Geosignals company, with the intent of collecting on field data, with information pairing via bluetooth to mobile platforms (smartphones) and sample collected dispatch through mobile or wireless networks. The prototype is ready, however it needs calibration tests with the sensors and adjustment of the algorithm with the data resulting from this research analysis. It utilizes reading system similar to the one used by the plate on MiCS-EK1 kit, performing the sensor's data reception on resistance (Ohms) form and , with that, being able to apply mathematical modelings in order to obtain ppm form data. The prototype also has the function of reading other metal oxide sensors for environment variables monitoring (humidity, temperature and atmospheric pressure) and gasses $\left(\mathrm{CO}_{2}, \mathrm{SO}_{2}, \mathrm{NO}_{2}, \mathrm{O}_{3}\right)$ [23] [24].

The calibration procedure was performed at Universidade de Brasilia's Geocronology Lab, linked to the Geosciences Institute-IG/UNB on the days (DD/MM/YYYY) 16/05/2014, 20/05/2014, 23/05/2014 and 10/06/ 2014, divided in five stages, described as:

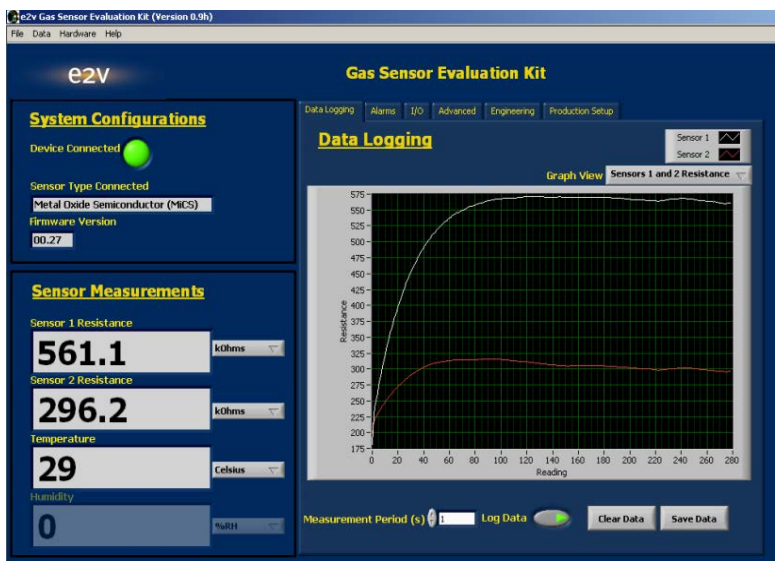

(a)

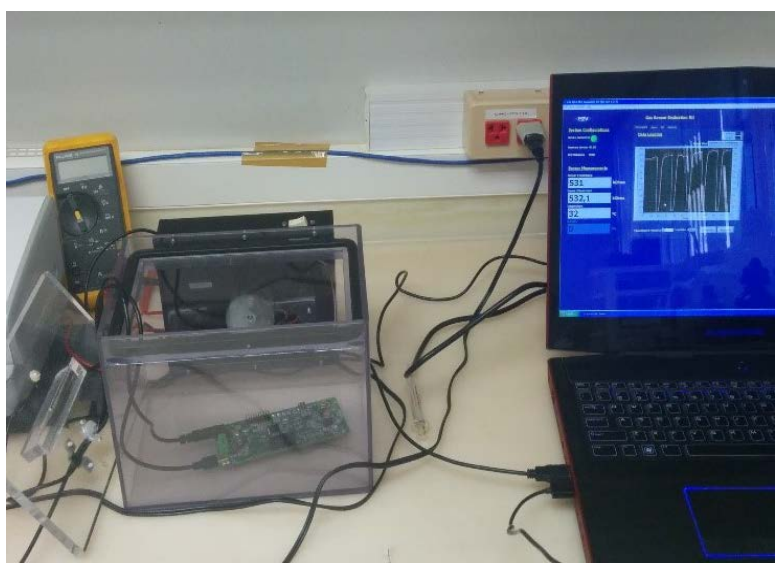

(b)

Figure 1. Kit MiCS-EK1 used to calibration the sensor. (a) Software Interface with readings of the slots; (b) Box of gas test (SR \# 3) with the kit MiCS-EK1 connected to evaluation software.

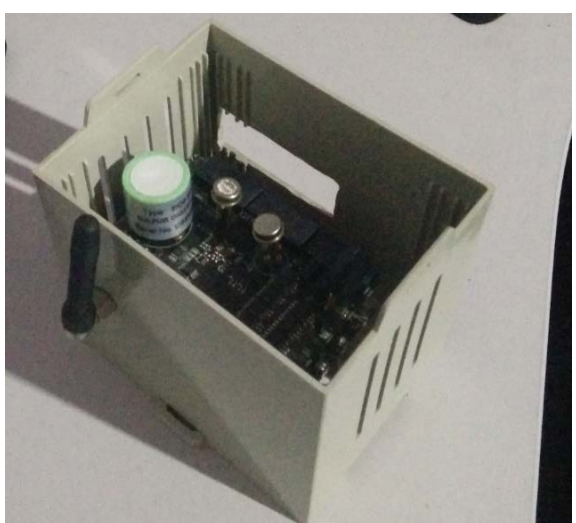

(a)

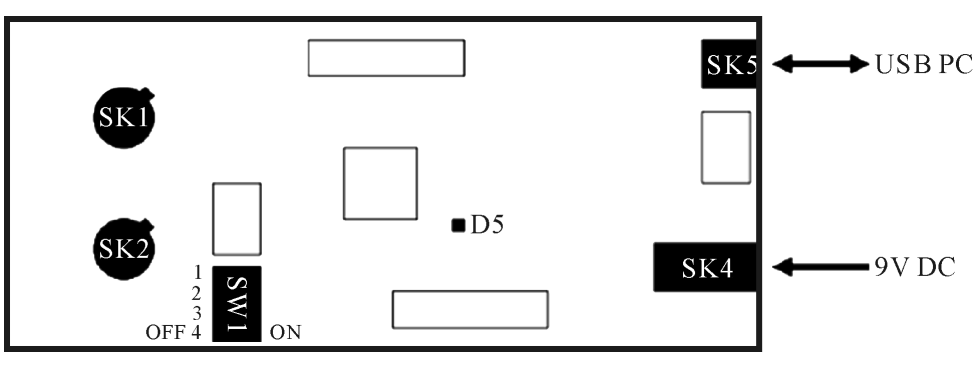

(b)

Figure 2. Prototype micro-controlled system. (a) For analysis of air quality; (b) Basic inteface kit MiCS-EK1. 
- Baseline;

- Controlled Volume Measuring;

- CO (Carbon Monoxide) Concentrations Conversion;

- Calibration Curve Generation;

- Simple Linear Regression Analysis;

- Monitoring Test.

To achieve the response time, both MiCS-5521 have been exposed to ambient air in the laboratory, performing readings during the period of continuous hours, with readings every second. The result was a data logging showing the stabilization time of the sensor's stabilization. For the use of the SR \# 3 box, the method specified by the manufacturer was used, keeping the stall opened in a clean environment and turning on the mixer for 2 - 3 minutes to guarantee that all contaminants had been removed from the box. After that, the box was closed with its lid. Subsequently, the syringe was filled with the volume of CO extracted from an output shaft of the gas tank valve. Thus, CO was injected in the box through a silicon septum. After that, the mixer (fan) was turned on for 30 seconds, 30 seconds of wait before the output reading observation. The box had its lid removed so it could return to the 2 - 3 minutes cleaning cycle. The CO volumes utilized on the calibration were $1 \mathrm{ml}, 2 \mathrm{ml}, 3 \mathrm{ml}, 4$ $\mathrm{ml}, 5 \mathrm{ml}$ and $6 \mathrm{ml}$. To each volume $(\mathrm{ml})$, the calibration was repeated ten times, in order to obtain a mean value for each volumetry.

Volume fraction or molar fraction unities are frequently utilized for gas concentration. In the analysis, the box's volume was added to each ml injected. The most utilized fraction of value is the ppm (parts per million in volume), defined by Equation (1) [23]:

$$
\operatorname{ppm}_{\mathrm{v}}=\frac{v_{i}}{v_{\text {total }}} \times 10^{6}
$$

where $v_{i}$ is the gas volume and $v_{\text {total }}$ air volume. The conversion from $\mathrm{ppm}$ to $\mathrm{mg} / \mathrm{m}^{3}$ [23], is described by Equation (2):

$$
\mathrm{mg} / \mathrm{m}^{3}=\frac{\mathrm{ppm}_{\mathrm{v}} \times \mathrm{M}}{24.45}
$$

where $\mathrm{ppm}_{\mathrm{v}}$ is the mol value of the solution, $\mathrm{M}$ the molecular mass of the air pollutant and the value 24.25 is a conversion factor that represents a mol of gas' volume.

The conversion equations depend on the temperature the conversion is desired (usually around $20^{\circ} \mathrm{C}$ to $25^{\circ} \mathrm{C}$ ). At a $1 \mathrm{~atm}$ atmospheric pressure (101,325 KPa or $1.01325 \mathrm{bar})$, and the general Equation (3) [24]:

$$
\mathrm{ppm}_{\mathrm{v}}=\left(\mathrm{mg} / \mathrm{m}^{3}\right) \times \frac{\left(273.15+{ }^{\circ} \mathrm{C}\right)}{(12.187) \times(\mathrm{M})}
$$

where $\mathrm{mg} / \mathrm{m}^{3}$ is the amount of milligrams of the pollutant per cubic meter of the ambient, $\mathrm{ppm}_{\mathrm{v}}$ the air pollutant concentration, as in parts per million per volume (the volume of pollutant gas per $10^{6}$ ambient air volumes), ${ }^{\circ} \mathrm{C}$ the ambient air temperature in Celsius degrees, 12.187 the value of universal gas constant, 273.15 is the $\mathrm{T}_{0}$ in Kelvin and M the pollutant's molecular mass.

\subsection{Analysis of Linear Regression}

The regression and the correlation are procedures utilized to estimate relations between variables that may exist in a certain population. The analysis of correlation and regression is done by studying sample data in order to understand if and how two or more variables are related one to the other in population. A regression model establishes a cause and effect relationship between two or more variables [24]. To estimate the expected value, a model is used to determinate the relationship between both variables by Equation (4):

$$
Y_{i}=\beta_{0}+\beta_{1} X_{i}+\varepsilon_{i}
$$

$Y_{i}$ is an explanatory variable (dependent); is the value you want to achieve, $\beta_{0}$ is a constant, that represents a straight line intersection with the vertical axis, $\beta_{l}$ is another constant, that represents the straight line slope, $X_{i}$ the explanatory variable (independent), represents the explanatory factor in the equation, $\varepsilon_{i}$ the term that includes all residual factors more the possible measurement errors. 


\subsection{Monitoring Test}

Day 06/06/2014, Brasilia's Bus Station was used as an outdoor reference point for measuring. Through it, the plugin Hawths Tools was generated, in the Arc GIS Info 10.2.2 ambient [25], a regular grid (grid) $20 \mathrm{~m} \times 20 \mathrm{~m}$ (Sampling Tools, in "creator vector grid" algorithm) (Figure 3(b)) and random samples ("generate random points"), with the intent of distributing peripheral points for the collection of air quality data. The entry to the random sampling was eight measurement points. The outdoor samples were performed with 5 minutes time for sample collection in each point.

Later, on 13/06/2014, there were made outdoor collections in the vincinity of Darcy Riberiro Campus, from Brasilia's University, on the main peripheral pathways of "minhocão" (Figure 3(c)). Another part of the outdoor collections were made during the World Cup (Switzerland $\times$ Equator), with the raise of 4 points on the event's surrounding area, which happened on 15/06/2014 at 1 pm, at Brasilia's National Stadium (Figure 3(d)). In order to collect indoor data, the University of Brasilia (UnB) was selected, located on Darcy Ribeiro Campus. There were divided into two measuring environments: ground floor and garage. The measurements made in ICC South Wing, ICC Central Wing and ICC North Wing. The indoor samples were performed on 13/06/2014, with 5 minutes time for sample collection in each point (Figure 4).

\subsection{Data Availability}

Once the air quality data gathering was over, the analysis spatialization into a dynamic digital map (WebGIS). Initially, a geodatabase was created using the indoor and outdoor analysis, in a vector format (point), with the fields described below (Table 1).

The publishing of the maps service on the tool ArcGIS Viewer of Flex [25], makes it easier to configure the final layout for the web application (Figure 5). The layers of base maps were inserted, comparative graphics tool, interactive design, identifier, subtitles, layer list, searcher, data printing and changing color themes. This set of interactive tools allows graphic analysis and dynamic queries, with the possibility of new entries of vector variables for future correlations with the data analyzed. Queries can be exported from the system in various formats (.xls, .doc, .pdf, etc.).

\section{Results and Discussion}

\subsection{Baseline}

The baseline shows similar behavior from both sensors still, their resistance values were different. That variation may be linked to a wear over time on the material used on the resistance, which may also can undergo interferences due to impurities on it, decreasing its reading capability. The Geocronology laboratory' ambient showed no major variation on its $\mathrm{CO}$ concentration, for it is a closed room. There is the temperature control $\left(25^{\circ} \mathrm{C}\right)$ and a minimum variation on the humidity, that remained in the range of $50 \%$ (recommended humidity for the datasheet calculation of a $\mathrm{R}_{S} / \mathrm{R}_{0}$ ) [26].

An important fact on the process of the baseline construction is that after 9 hours collecting data (Figure 6) (Table 2) in the laboratory's ambient, both sensors had their readings stabilized and when a sudden change occurred, and then a new stabilization at a higher level. This event may have been caused by a crossed sensibility that happened after the laboratory's glassware was cleaned with alcohol, in a closed ambient. This interference had been observed previously in other studies. Alcohol and humidity sensors are necessary when a micro controlled system that uses those kinds of machinery to calculate the interferences of both varieties. As a consequence, it is indicated that a controlled humidity environment is created for the system's module [21] [22].

Table 1. Description of fields defined in the table of attributes of the analyses.

\begin{tabular}{|c|c|c|c|c|c|}
\hline Type & Data & Fields & Description & Environment & Date of acquisition \\
\hline Point & Location & $\begin{array}{l}\text { Date (Datetime); Hour (Datetime); } \\
\text { Temperature (String); Humidity (String); } \\
\text { Sensor_1_R (String); PPM_Senso (Dou- } \\
\text { ble); Sensor_2_R (String); PPM_Sen_1 } \\
\text { (Double); Latitude } \\
\text { (Double); Longitude (Double) }\end{array}$ & Local description & Outdoor or indoor & Day/Month/Year \\
\hline
\end{tabular}




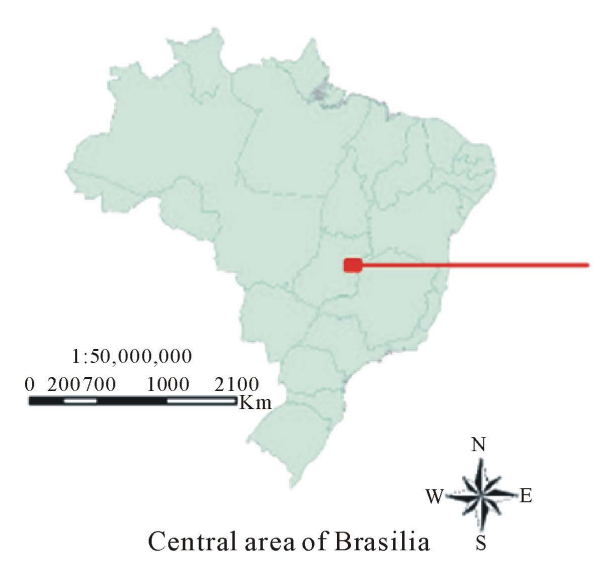

$47^{\circ} 54^{\prime} 10^{\prime \prime} \mathrm{W} \quad 47^{\circ} 53^{\prime} 20^{\prime \prime} \mathrm{W} \quad 47^{\circ} 52^{\prime} 30^{\prime \prime} \mathrm{W}$
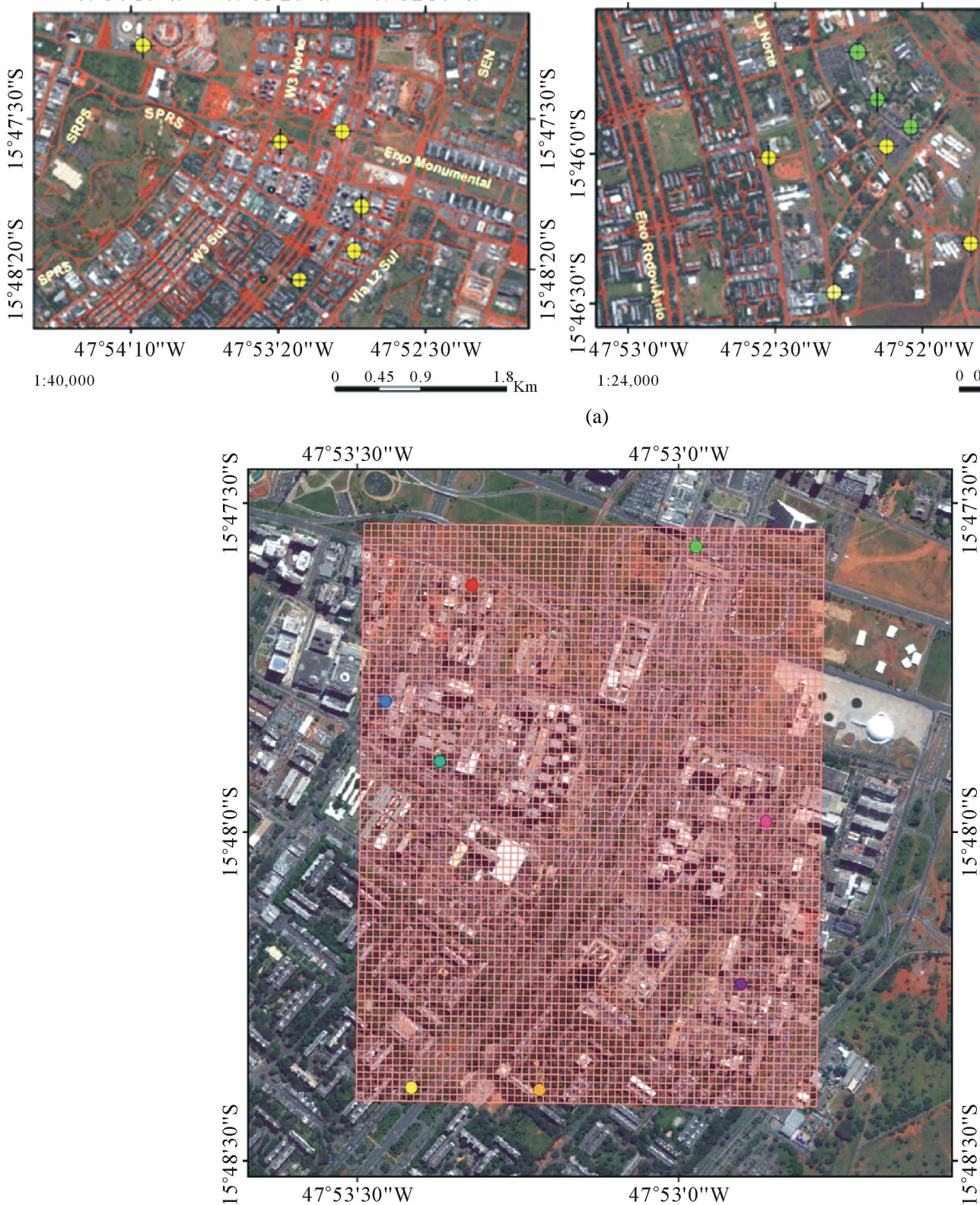

(b)

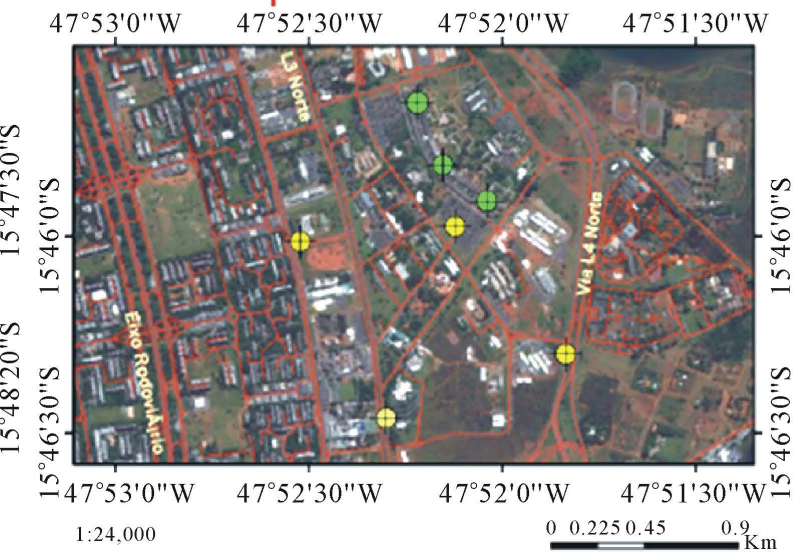

(a)

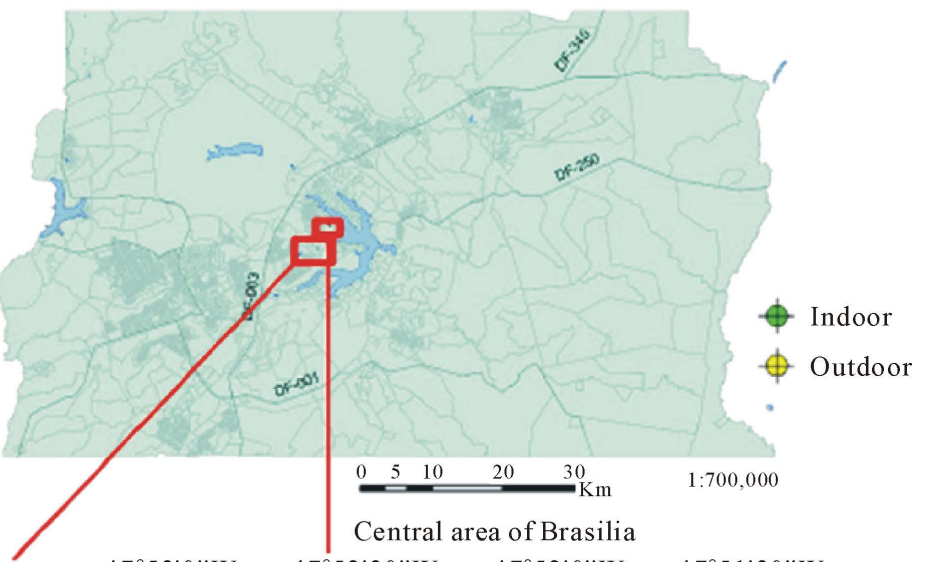




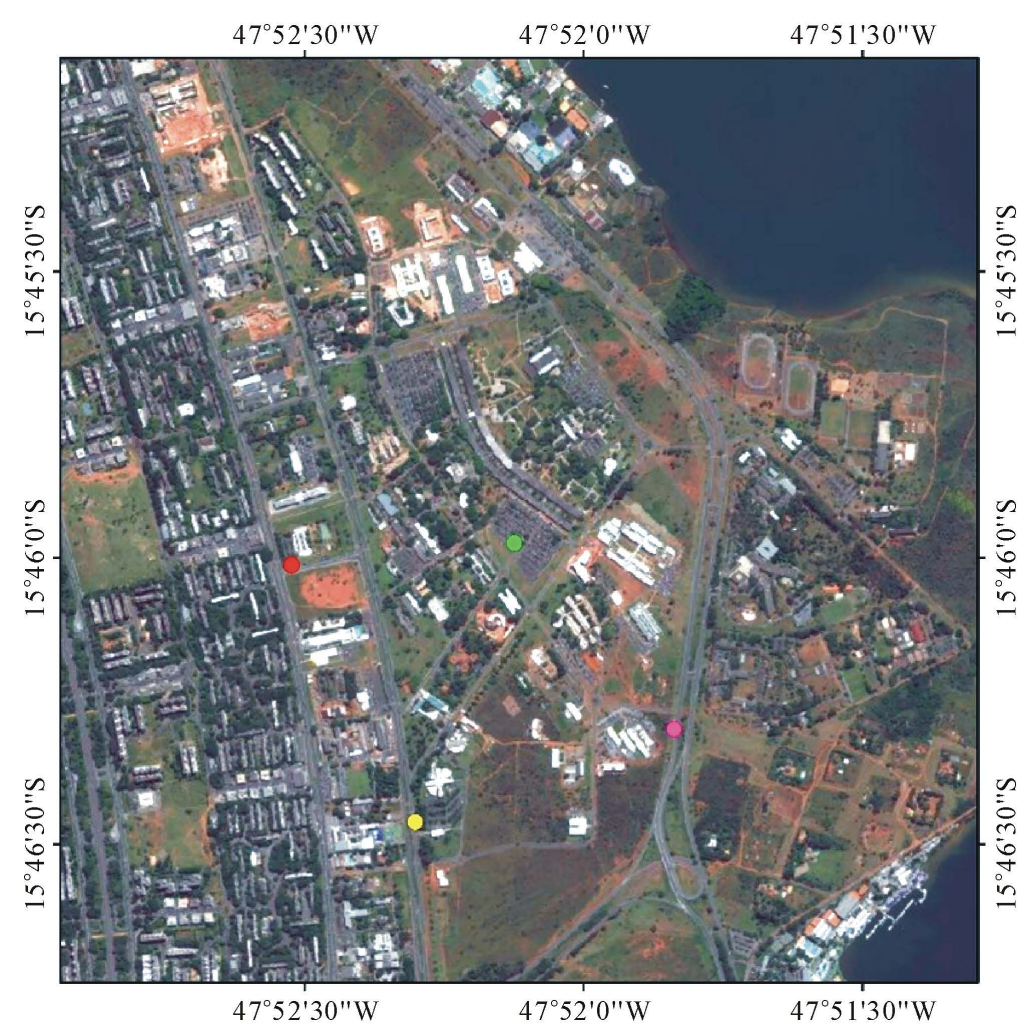

(c)

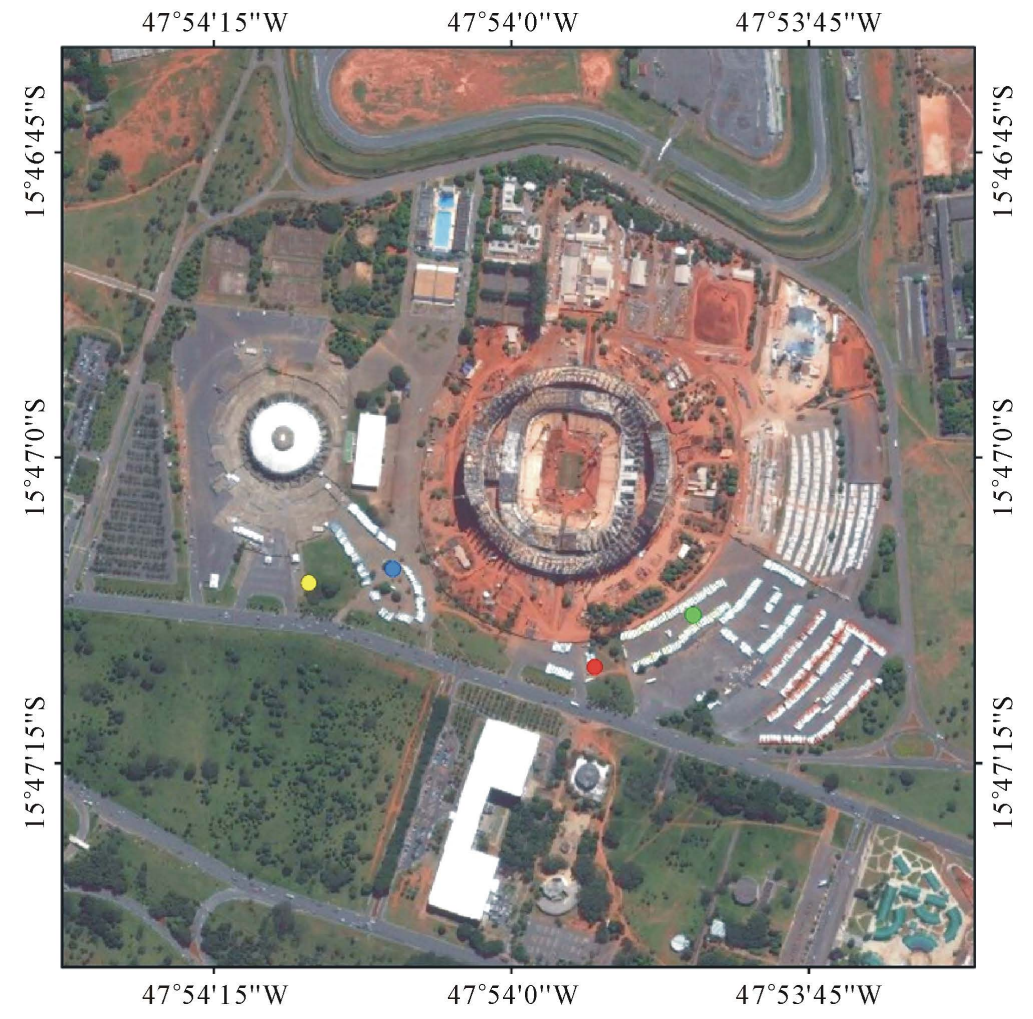

(d)

Figure 3. Map with points of outdoor and indoor collections in: (a) Map with the spot selected to available the system; (b) The hot spots in the central Brasilia; (c) Campus Darcy Ribeiro, the University of Brasilia; (d) Brasilia National Stadium. 


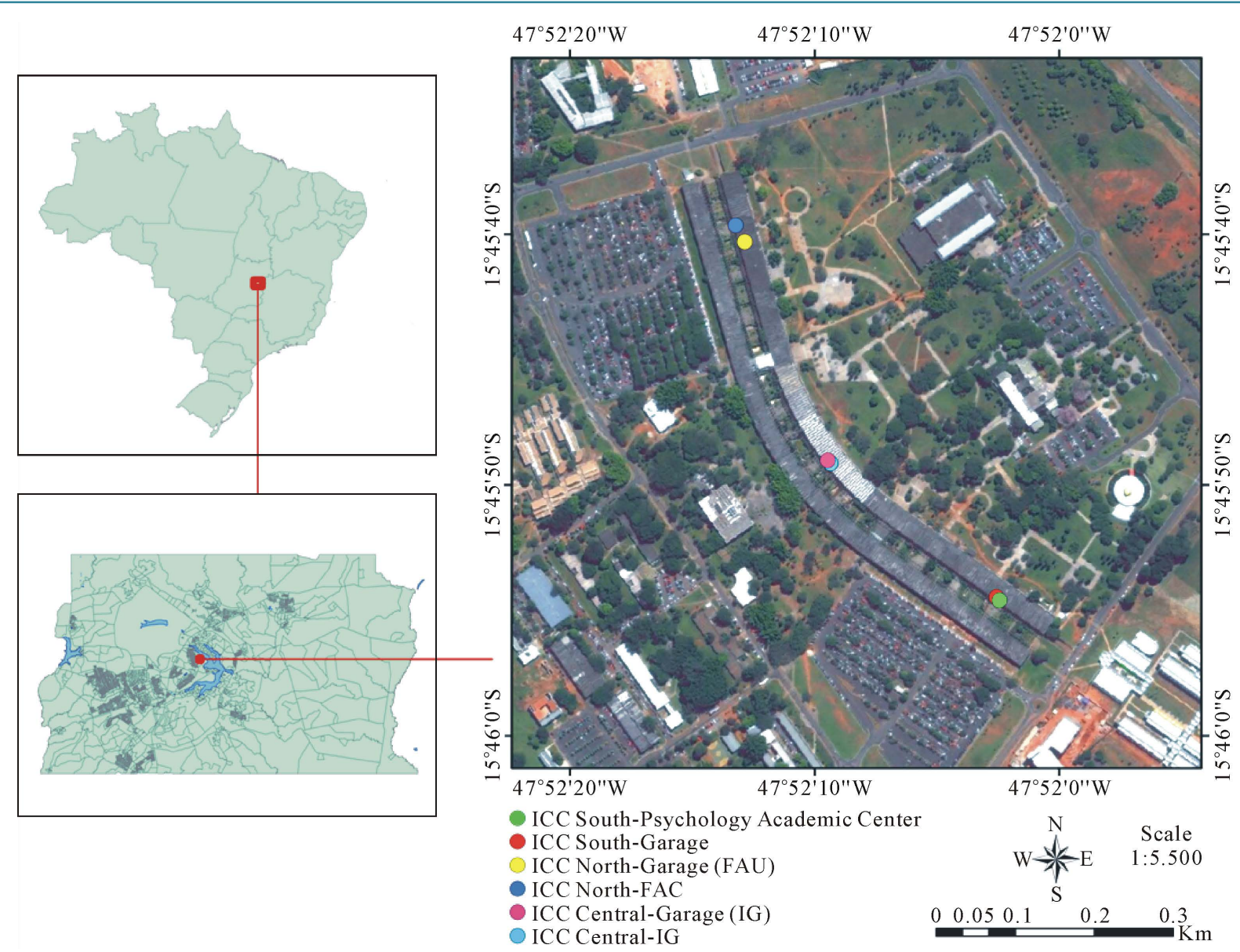

Figure 4. Map with points of indoor collections in University of Brasilia.

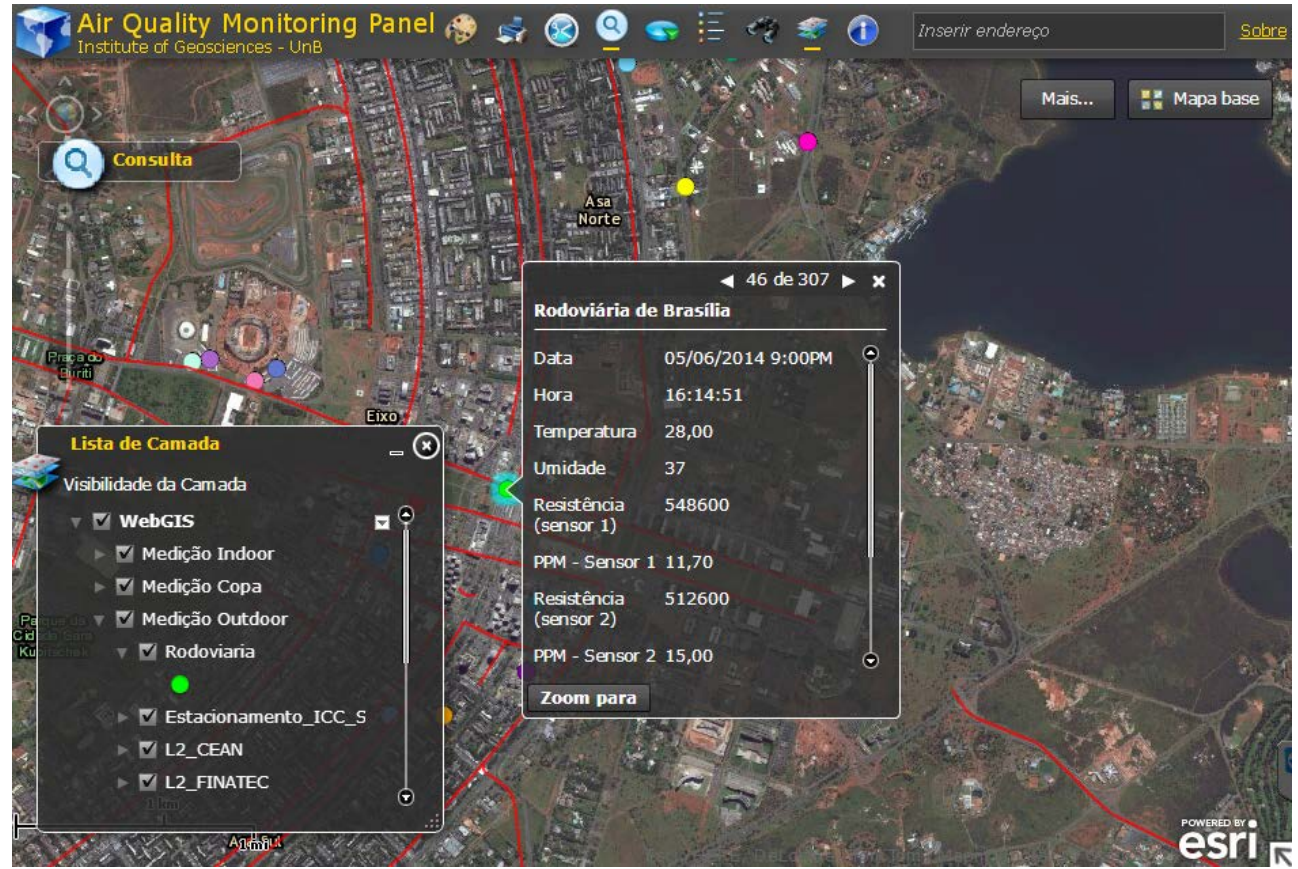

Figure 5. WebGIS system screen with the information of the outdoor and indoor measurements. 


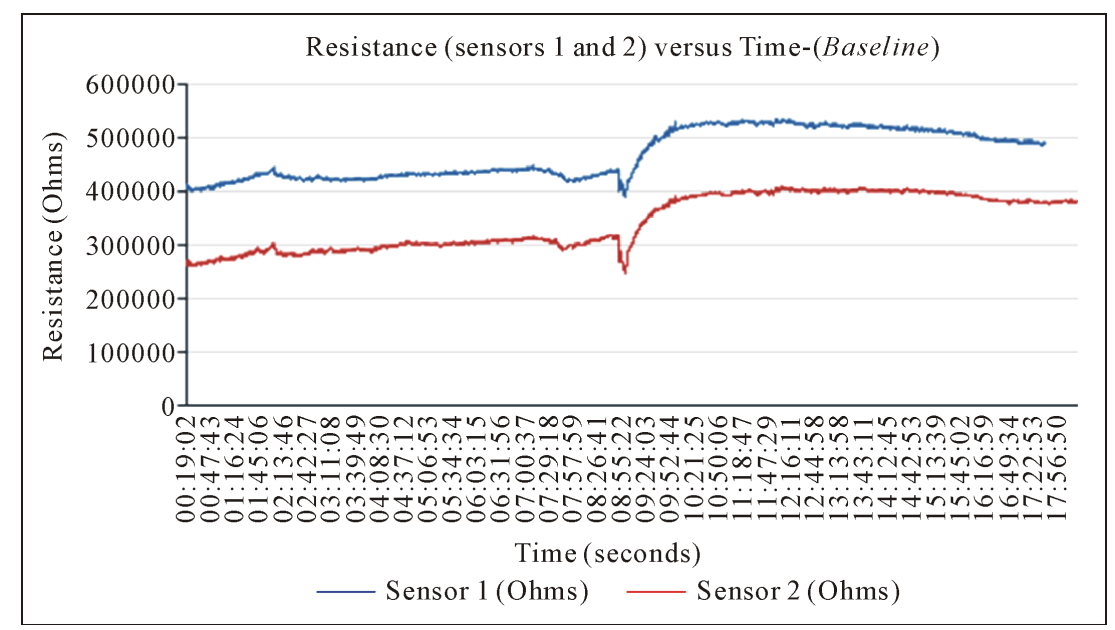

Figure 6. Baseline resistance (Ohms) obtained over approximately 18 hours.

Table 2. The mean baseline for sensors 1 and $2\left(R_{0}\right)$.

\begin{tabular}{cc}
\hline Sensor 1 (Ohms) & Sensor 2 (Ohms) \\
\hline 468,958 & 341,631 \\
\hline
\end{tabular}

\subsection{Responses to $\mathrm{CO}(\mathrm{ml})$ Injections}

This procedure was carried out using the test box Figaro (Figure 1) acrylic material with a total volume of 5.4 liters being confined for the $\mathrm{CO}(\mathrm{ml})$ injections. Two sensors were used, one being unused (sensor 1 ) and the other with about a year and a half of use (sensor 2). The relation between enclosed volume the (5.4 liters) and the concentration $\mathrm{ppm}_{\mathrm{v}}$ of $\mathrm{CO}$ box, calculated according to (Figure 7). Metal oxide sensors demonstrate a response to the presence of $\mathrm{CO}$ gas from concentrations above $10 \mathrm{ppm}$. According to the sensors manucturer's datasheet [21], the detection limit is $1000 \mathrm{ppm}$. Using such information and the calculation of the volumetric data (Figure 8(a), Figure 8(b)) the box's volume reaches this concentration at $6 \mathrm{ml}$.

It can be seen that upon injection of $6 \mathrm{ml}$ (Figure 8(a), Figure 8(b)), the resistance decreases to the point wherein the metal oxide material becomes unable to detect the target gas, having the resistance in its lowest reading.

The higher the temperature reached by the resistance $\left(700^{\circ} \mathrm{C}\right.$ to $\left.900^{\circ} \mathrm{C}\right)$, the higher the sensitivity and selectivity of the sensor at low concentrations of CO. A greater amount of energy must be provided to the controlled micro system, so it can reach that temperature [21]. It can be seen that the sensor behaves in an inverse relationship. The larger the target gas volume, the smaller are the resistance values (Figure 9). From these data we carried out a basic statistical analysis in order to verify data quality. The mean (10 injections) was calculated, the standard deviation and the variation coefficient of resistance (Ohms) of the sensors for each volume (ml) injected by Equation (5).

$$
C V=\frac{\sigma(x)}{\bar{x}} \times 100
$$

where $\sigma(x)$ is the standard deviation and $\bar{x}$ is mean.

The coefficient of variation values are low for all injections (ml), indicating that for both sensors, the data dispersion from the average is small, i.e., the dispersion is relative low and the results can be considered good (Table 3, Table 4).

The result of the correlation coefficient $(r)$ appeared around 0.96 among the resistance achieved in readings between both sensors (Table 5). The sum of the products, covariance of the population and sample covariance did not indicate significant variations, demonstrating that the resistance kept close variations, of the total of injections (ml). However, the sensor 2 presented significant differences of values of resistance (Ohms) read, when compared to the sensor 1 and may be related to the interference mentioned previously. This fact must be taken 


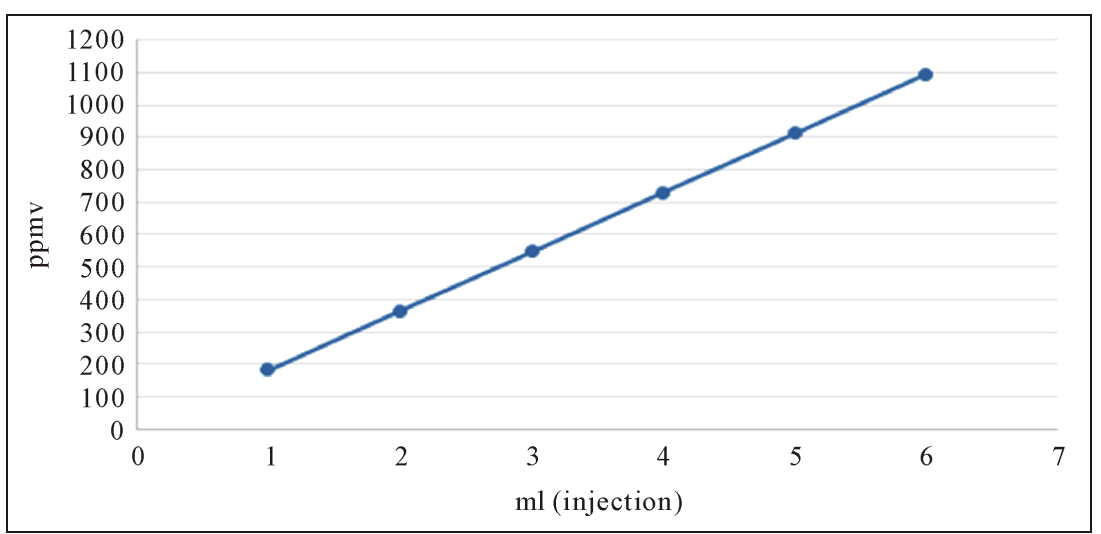

Figure 7. Relationship between the $\mathrm{ppm}_{\mathrm{v}}$ on a volume of the box by volumetry of the injections.

\begin{tabular}{|r|r|r|r|}
\hline 100000 \\
$90000-$
\end{tabular}

(a)

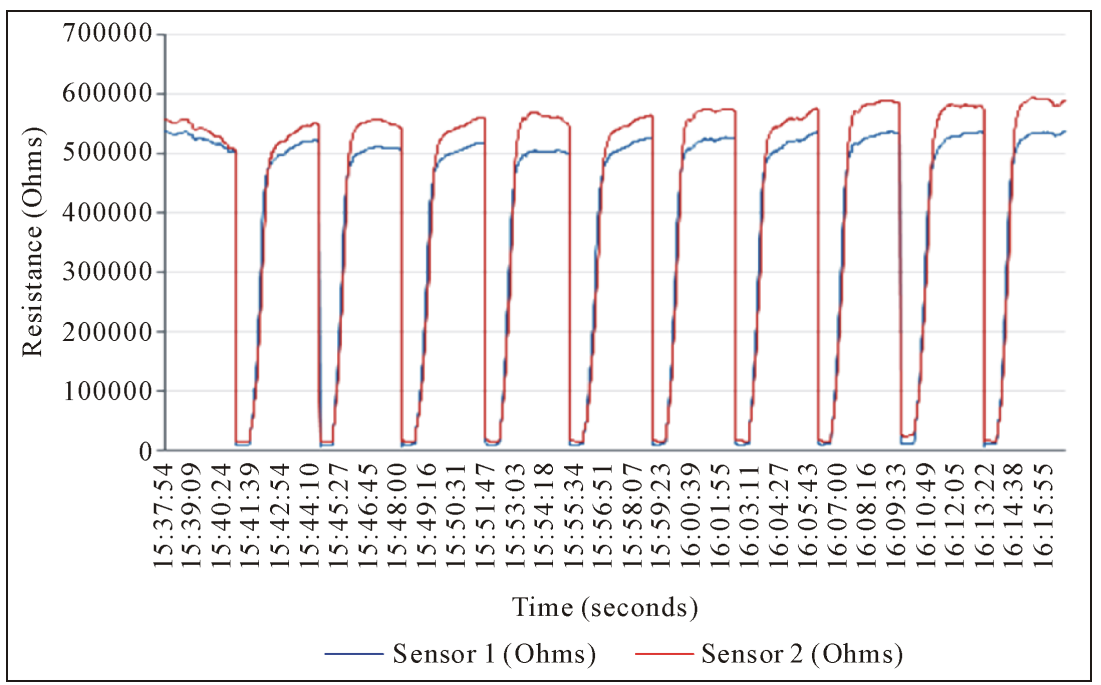

(b)

Figure 8. (a) Response of the resistance (Ohms) of the sensors 1 and 2 to $6 \mathrm{ml}$ injection (10 repetitions) of CO (30 seconds); (b) Response of the resistance $\mathrm{R}_{\mathrm{s}}$ (Ohms) the 10 repetitions of injections ( $6 \mathrm{ml} \mathrm{CO}$ ). 

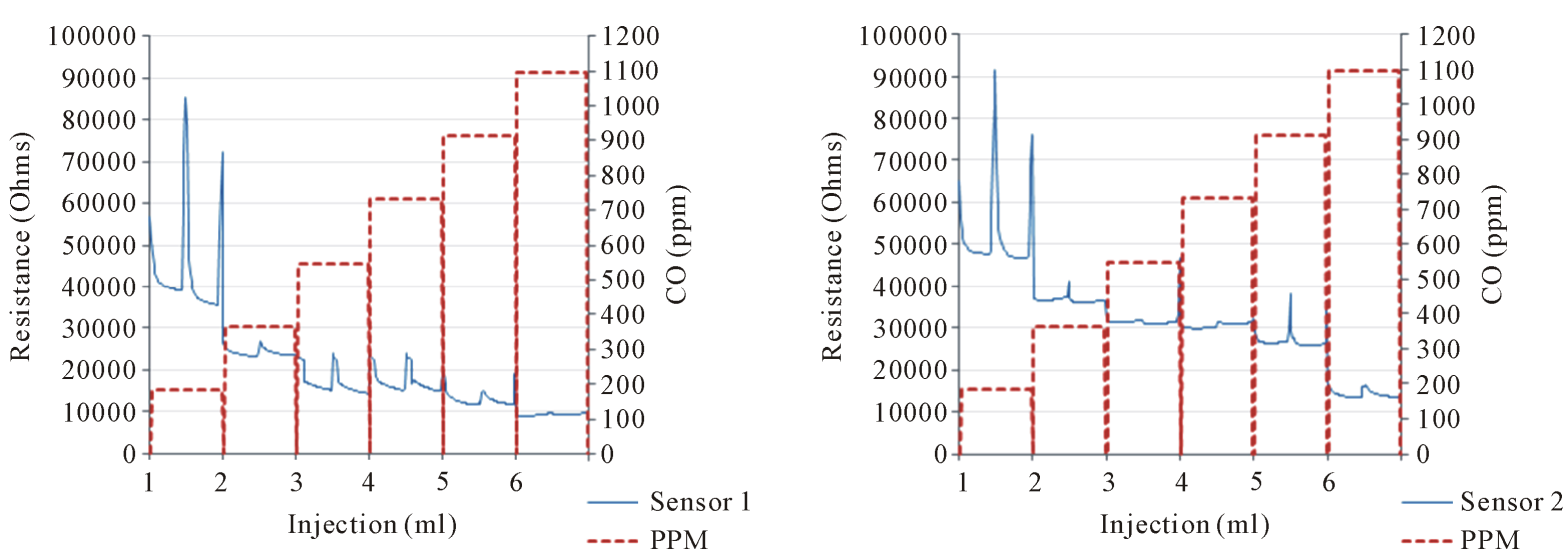

Figure 9. Response of resistance $\mathrm{R}_{\mathrm{s}}$ (Ohms) in 2 moments of each injection (ml), demonstrating the inverse relation with the concentration. Sensor 1 -left graphic; Sensor 2-right graphic.

Table 3. Mean, standard deviation and coefficient of variation (\%) of resistance (Ohms) injected volume (ml)—sensor 1.

\begin{tabular}{cccc}
\hline Sensor 1 (Ohms) & Mean & Standard deviation & Coefficient of variation (\%) \\
\hline $1 \mathrm{ml}$ & 41,833 & 1341 & 3.20 \\
$2 \mathrm{ml}$ & 25,910 & 622 & 2.40 \\
$3 \mathrm{ml}$ & 23,894 & 481 & 2.01 \\
$4 \mathrm{ml}$ & 15,978 & 130 & 0.81 \\
$5 \mathrm{ml}$ & 13,366 & 410 & 3.07 \\
$6 \mathrm{ml}$ & 9350 & 139 & 1.49 \\
\hline
\end{tabular}

Table 4. Mean, standard deviation and coefficient of variation (\%) of resistance (Ohms) injected volume (ml)—sensor 2.

\begin{tabular}{cccc}
\hline Sensor 2 (Ohms) & Mean & Standard deviation & Coefficient of variation (\%) \\
\hline $1 \mathrm{ml}$ & 51,068 & 605 & 1.19 \\
$2 \mathrm{ml}$ & 35,879 & 752 & 2.10 \\
$3 \mathrm{ml}$ & 31,424 & 434 & 1.38 \\
$4 \mathrm{ml}$ & 30,766 & 602 & 1.96 \\
$5 \mathrm{ml}$ & 17,553 & 415 & 2.37 \\
$6 \mathrm{ml}$ & 14,271 & 162 & 1.14 \\
\hline
\end{tabular}

Table 5. Comparison between the means of the resistance (Ohms) of the injections (1 $\mathrm{ml}$ to 6 $\mathrm{ml}$ ) of the sensor 1 and sensor 2 , their covariances and the correlation coefficient.

\begin{tabular}{ccc}
\hline & Sensor 1 & Sensor 2 \\
\hline Mean (Resistance) & 21,722 & 30,160 \\
Sum of products & $-103,981$ & $-119,810$ \\
Covariance of the population & $-17,330$ & $-19,968$ \\
Sample covariance & $-20,796$ & $-23,962$ \\
Sample covariance & 21,722 & 30,160 \\
Correlation (Resistance (Ohms)) & $r=0.96$ \\
\hline
\end{tabular}


into consideration and the calibration curve should be reviewed, as there is signal degradation and consequently a smaller concentration reading.

\subsection{Calibration by the Linear Regression Method}

For this study, two variables were correlated, the resistance (Ohms) and the volume of injections (ml). There is a cause-effect relationship observed in the procedure, when there is injection (ml) in the box, the resistance (Ohms) tends to fall. Good correlation between the resistance reading data per injected volume to the sensor $1(r=0.88)$ also found for the sensor $2(r=0.89)$ (Figure 10).

Around $88 \%$ (sensor 1 ) and $89 \%$ (sensor 2 ) the variability of the resistance (Ohms) can be explained by variability in CO concentration (ppm). The remainder (12\% to $11 \%$ ) can not be explained by other factors present, such as cross-sensitivity of interference with other gases, lifetime reduction, foreign particles in the layer of the material that makes up the resistance, which are factors causing significant changes in the readings. The straight line's behavior for both sensors indicate that the higher the concentration (CO), the lower the resistance (Ohms). It was observed that after the box volume (5.4 liters) was mixed with $6 \mathrm{ml}$, equivalent to $1096 \mathrm{ppm}_{\mathrm{v}}$, exceeding the limit of detection for this sensor, the response sensitivity of the resistance is reduced with particles dispersing in the microenvironment. By analyzing the CO sensor data with the MiCS-5521 from another study, it was observed, comparing the metal oxide sensors, that some have a small influence of temperature, while others tend to have a great influence and may have a positive or negative correlation with this variable. Furthermore, the influence of the sensor's temperature may change over time with use and seasonal changes. Also mentions that the results of measurements of the sensors MiCS-5521 sensors next to the station a traditional station, differ significantly from the results obtained in the laboratory. For the same sensor model, the author found very strong correlation $(r=0.99)$ when comparing the resistance reading by volume of gas (CO) in the laboratory [27]-[29].

\subsection{Results of Indoor and Outdoor Analysis}

The outdoor analyzes sought to demonstrate the local situations of interactions with CO readings. The objective was to assess behaviors adverse to those obtained in the laboratory, in environments that have heterogeneous characteristics. Such a proposal is given in order to take readings with similar changes for the two sensors. The monitoring of air quality in outdoor environment involves preparation for the micro-controlled system, in order to avoid interference in reading. The intention of the field analysis for this study is to understand the interference factors in the resistance material from MiCS-5521 sensor. With that, auxiliate in future work with this sensor model [24]. One of the points assessed was the square of the SQS 202 (Figure 11(a)), in which the sensors demonstrated very close responses in resistance readings. Being a region with residential character, with reduced car traffic in the analyzed time, the resistance has not oscillated considerably.

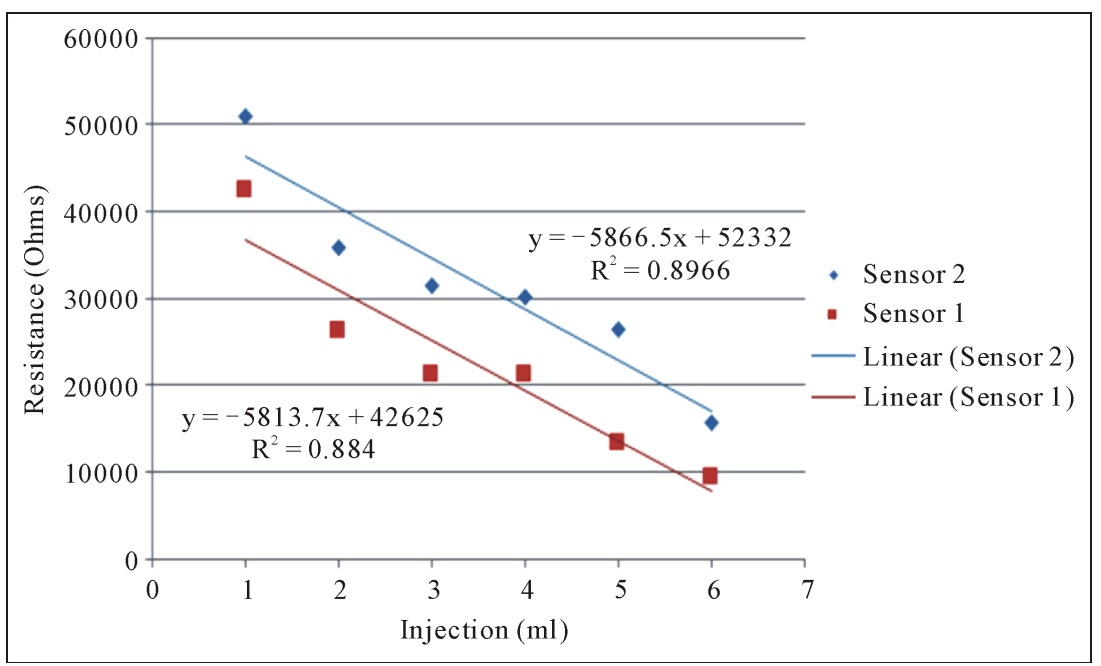

Figure 10. Coefficient of determination of resistance (Ohms) in relation to injection (ml) of CO. 


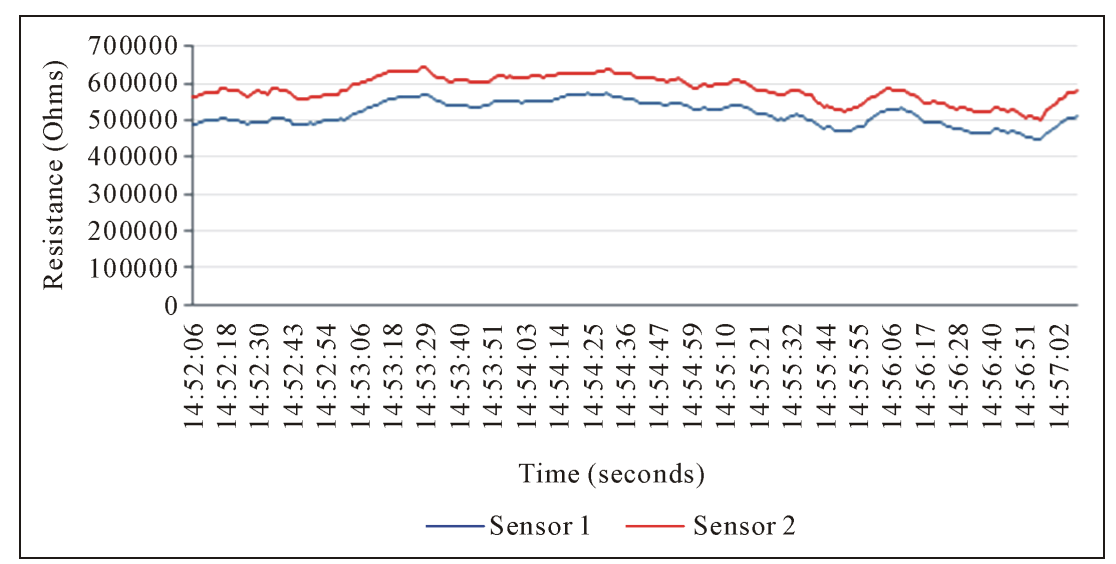

(a)

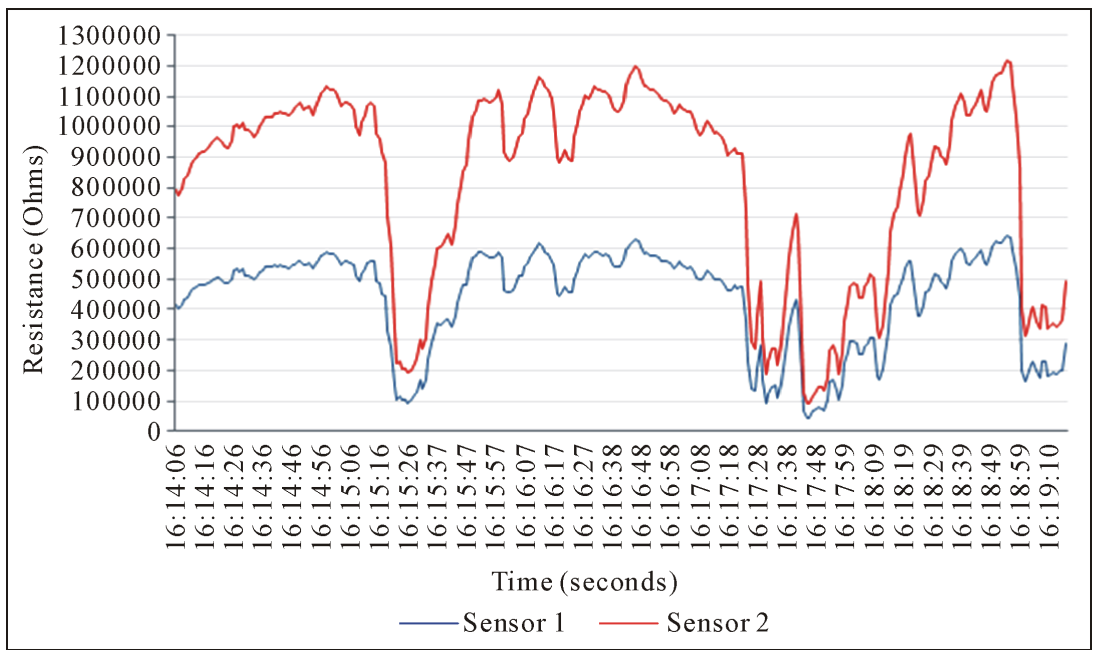

(b)

Figure 11. Outdoor sampling: (a) In the square of the SQS 202; (b) Bus central station of Brasilia.

Another rated point was the main bus station of Brasilia, which is a critical point of emissions in central Brasilia. At times, the values of fluctuations in the resistance of the sensors were almost four times higher than that presented in other regions analyzed. The fleet circulating in this region is diverse, with large cars (public bus), and be located in the road axis (Figure 11(b)).

The variations found in the ICC South Wing, near the Psychology Academic Center and garage, did not show large fluctuations in the resistance of the sensors, analyzing it in the garage, the reading has remained largely stable and in the vicinity of the Academic Center, showing decay in reading. However, when there is movement of vehicles on the internal via of the garage that can be subject to alteration (Figure 12).

The calibration of the sensors ( 1 and 2 ) indicated a strong correlation between the resistance (Ohms) and the injection of volumetric (ml), with values $r$ exceeding 0.8 . The use of these sensors in micro-controlled systems for monitoring air quality, the use of the generated calibration equations is needed. Its application is given directly to the reading software, where the data processing algorithms (readings) are stored. However, the results of the present study were similar to the results of other studies, which had the low-cost sensors (MiCS-5521) calibration as its purpose [27]-[29].

\subsection{WebGIS Panel Results}

The results analyzed in indoor and outdoor surveys were georeferenced in order to make the data available in an online panel format (WebGIS). In this sense, tools (widgets) have been configured for interaction with the 


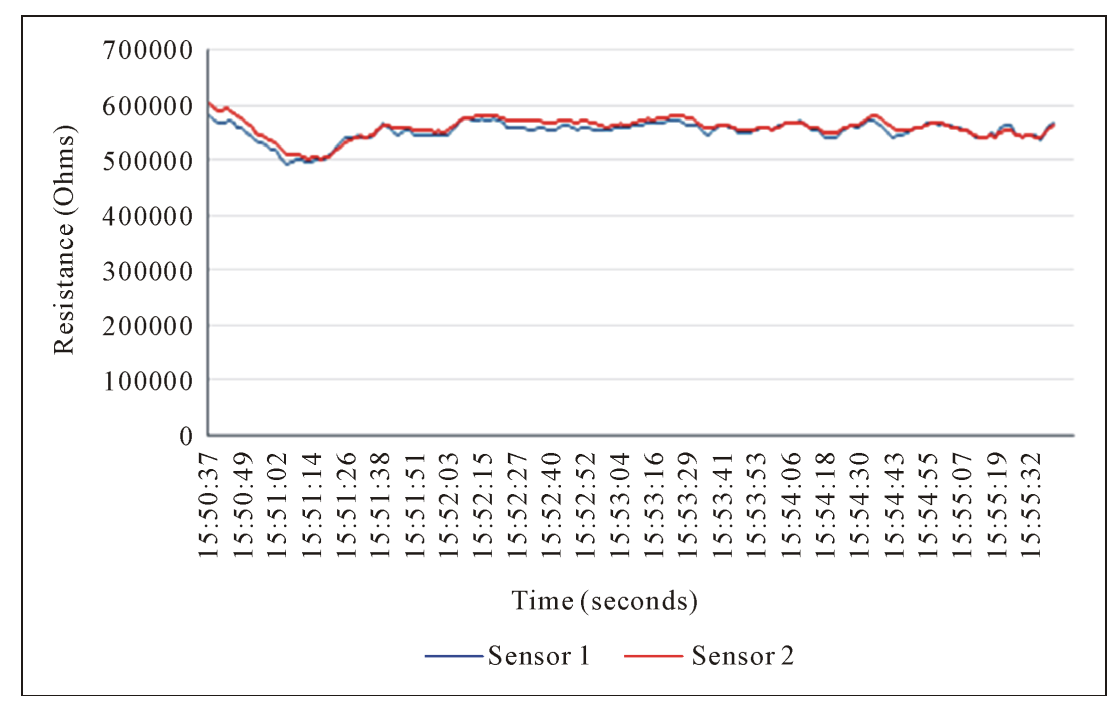

Figure 12. Indoor sampling in Academic Center of Psychology (CA).

available information. A consultation widget was implemented to allow end users to query information by executing a predefined query. At the end-user level, query execution is simple and is performed with a single button click, working in a single layer for consultation (Figure 13(a)). For graphical analysis of the variations of the resistance (Ohms) and time, was implemented graphic widget, so that comparisons have been collected at each point (Figure 13(b)).

\section{Conclusions}

The calibration of the sensors ( 1 and 2 ) showed strong correlation between the resistance (Ohms) and the injection (ml) volumetric, the $r$ values exceeding 0.8 . The use of these sensors in micro-controlled systems for monitoring air quality, the use of the generated calibration equations is needed. Its application occurs directly in the reading software, which stored input data processing algorithms (reads). For the sensor 1 have the following Equation (5) with $r=0.88$.

$$
y=-3634.9 x+29491
$$

For the sensor $2(r=0.89)$, Equation (6).

$$
y=-5866.5 x+52333
$$

However, the results of the present study were similar to the results of other studies, which had the goal of calibration low-cost sensors (MiCS-5521) [21]. Sensors MiCS-5525 are for obtaining CO reading data. To do this, we conducted a linear regression analysis of sensed data generated by sensor MiCS-5521. Based on the results of linear regression, a calibration equation was created, used to correct the readings of sensor MiCS-5525 from the sensor MiCS-5521, which showed a strong correlation $(r=0.85)$ [22].

Thus, with some restrictions, the presented hypothesis is confirmed - there is a strong correlation $(r)$ in the volumetric samples taken for the sensors. However, the restriction to confirm the hypothesis made on the calibration test, which proved to be the sensor 1 is within the range (datasheet) as established by the manufacturer of the oscillating resistance in $\mathrm{CO}(\mathrm{ml})$ concentration injected. The sensor 1 is new, use of wear-free. Therefore, it is emphasized that compared the responses analyzed, the hypothesis was confirmed, and the $6 \mathrm{ml}$ volumes larger than the sensor 1 responds with the decay close to the zero resistance (Ohms), indicating that it has more CO concentration readings in these ranges. Thus, it can be said that both sensors have the potential to be used in emission measurements generated in urban traffic, as alternative equipment monitoring air quality, adjusted sensor 2 depending on the sensor 1 accuracy. However, they are not suitable for use as an air quality autonomous sensor due to cross-sensitivity problems. When combined with other sensors in a multisensor system can eliminate the interference. Another detail that makes it feasible for a monitoring system is its low power consumption (less than $100 \mathrm{~mW}$ ). 


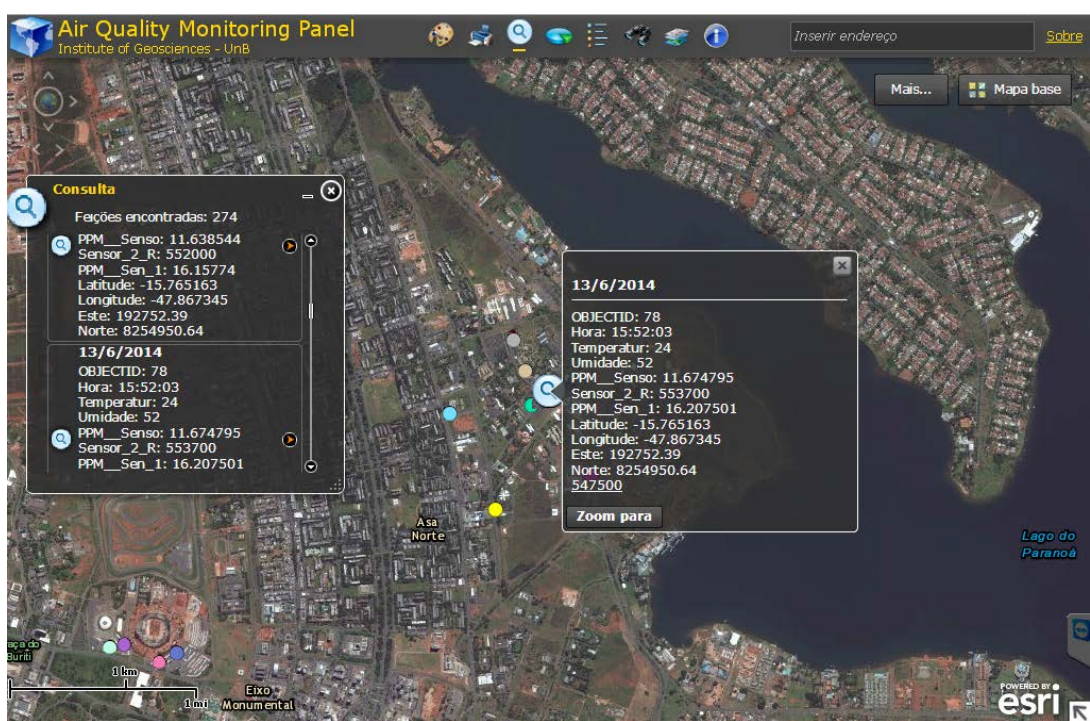

(a)

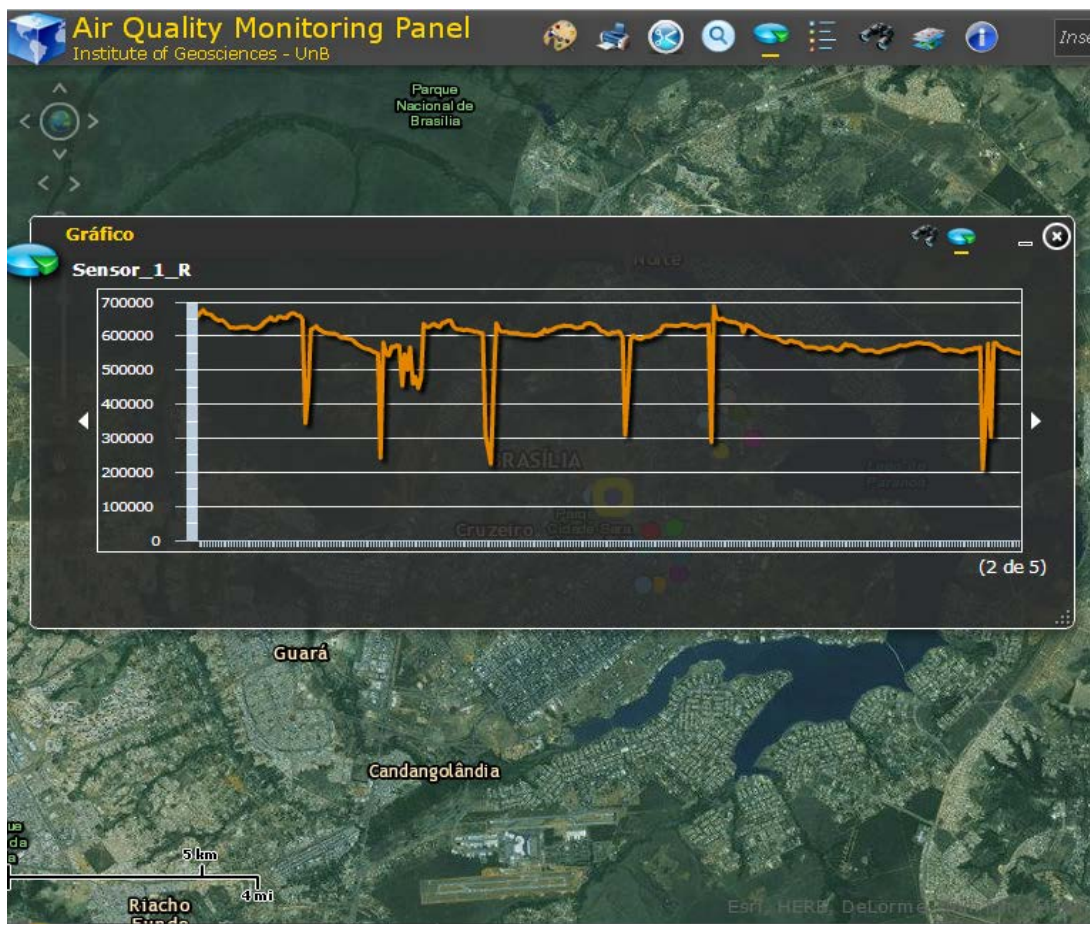

(b)

Figure 13. (a) WebGIS interface panel screen with the query tool; (b) Panel screen to the graphic tool show the concentration CO variation (line type).

The results of the analyses pointed outdoor critical areas, with high variations in resistance of the sensors, such as the Central Bus station of Brasilia and the Commercial Sector South.

It is emphasized that the possibility of comparison with traditional monitoring stations of air quality that have CO sensors (reference), the data can be validated with the precision found in these detectors. It is emphasized that continuous tests in indoor analysis check, over time, the sources that may come to contribute to CO in the ICC environment. Analyses did not detect any source that contributed significantly to a considerable variation in the concentration of CO.

The WebGIS system (Panel) was presented as a suitable platform for the provision of data collected in the en- 
vironments mentioned above. It demonstrated the dynamic configuration capabilities in question tools (widgets) customization. It showed that WebGIS has eased in upgrading with the addition of new data in an automatic manner, and can connect from a preconfigured database with the application, or from the update a project built on ArcGIS Desktop environment, with connection to ArcGIS Server. Numerous configuration possibilities for displaying the same platform indicate that the created panel can suit any setting that may be redesigned, from new needs.

The research presented few limitations, such as not monitoring environment variables, which can cause crosssensitivity, contained in lab space. It takes a field calibration with the reference stations, for comparison with the procedure performed in a controlled environment. If calibration is important to a larger number of sensor units MiCS-5521, reaching a result with a larger universe sample and then data with greater confidence. Finally, assessments in different settings of indoor and outdoor environments have the CO behavior panorama, in the diversity of these situations.

\section{Acknowledgements}

The CAPES for the scholarship to the first author during the development his master. The Laboratory of Remote Sensing and Spatial Analysis (LSRAE) and the Geocronology for the technical support to this research. ESRI for providing the package of tools that make up the through ArcGIS 10 family of the contract number 2011 MLK 8733 and IMAGEM for the support and feasibility of establishing the terms of use and between the IG and the support of ESRI software.

\section{References}

[1] Cohen, A.J., Anderson, H.R., Ostra, B., Pandey, K.D., Krzyzanowski, M., Kunzli, N., Guschmidt, K., Pope, A., Romieu, I., Samet, J.M. and Smith, K. (2005) The Global Burden of Disease Due to Outdoor Air Pollution. Journal of Toxicology and Environmental Health, Part A, 68, 1-7.

[2] Thepanondh, S. and Toruska, W. (2011) Proximity Analysis of Air Pollution Exposure and Its Potential Risk. Journal of Environmental Monitoring, 13, 1264-1270. http://dx.doi.org/10.1039/c0em00486c

[3] Gorai, A.K., Francis Tuluri, F. and Tchounwou, P.B. (2014) A GIS Based Approach for Assessing the Association between Air Pollution and Asthma in New York State, USA. International Journal of Environmental Research and Public Health, 11, 4845-4869

[4] ATSDR (2014) Agency for Toxic Substances and Disease Registry. Air Pollution. Atlanta, United States of America.

[5] Nandasena, S., Wickremasinghe, A.R. and Sathiakumar, N. (2012) Respiratory Health Status of Children from Two Different Air Pollution Exposure Settings of Sri Lanka: A Cross-Sectional Study. American Journal of Industrial Medicine.

[6] WHO (2013) Outdoor Air Pollution a Leading Environmental Cause of Cancer Deaths. http://www.iarc.fr/en/media-centre/iarcnews/pdf/pr221_E.pdf

[7] Levy, J.I., Hammitt, J.K. and Spengler, J.D. (2000) Estimating the Mortality Impacts of Particulate Matter: What Can Be Learned from between Study Variability? Environmental Health Perspectives, 108, 109-117.

[8] Schwartz, J. (2004) The Effects of Particulate Air Pollution on Daily Deaths: A Multi-City Case-Crossover Analysis. Occupational and Environmental Medicine, 61, 956-961.

[9] Pope III, C.A., Burnett, R.T., Thurston, G.D., Thun, M.J., Calle, E.E., Krewski, D. and Godleski, J.J. Cardiovascular Mortality and Long-Term Exposure to Particulate Air Pollution: Epidemiological Evidence of General Pathophysiological Pathways of Disease. Circulation, 109, 71-77.

[10] Hasenfratz, D., Saukh, O., Sturzenegger, S. and Thiele, L. (2012) Participatory Air Pollution Monitoring Using Smartphones. Zurich.

[11] Kanaroglou, P.S., Jerrett, M., Morrison, J., et al. (2005) Establishing an Air Pollution Monitoring Network for IntraUrban Population Exposure Assessment: A Location-Allocation Approach. Atmospheric Environment, 39, $2399-2409$. http://dx.doi.org/10.1016/j.atmosenv.2004.06.049

[12] Sivaraman, V., Carrapetta, J., Hu, K. and Luxan, B. (2010) HazeWatch: A Participatory Sensor System for Monitoring Air Pollution in Sydney. 38th Annual IEEE Conference on Local Computer Networks-Workshops, Australia, 56-64.

[13] Hasenfratz, D., Saukh, O. and Thiele, L. (2012) On-the-Fly Calibration of Low-Cost Gas Sensors. Computer Engineering and Networks Laboratory, Zurich.

[14] Réquia, W.J.R., Koutrakis, P. and Roig, H.L. (2015) Spatial Distribution of Vehicle Emission Inventories in the Fed- 
eral District, Brazil. Atmospheric Environment, in press.

[15] CETESB. Environmental Sanitation Technology Company (2013) Air Quality. São Paulo.

[16] CAESB. Environmental Sanitation Company of the FD (2011) Base Data: Location and Classification of Hydrometers Are Federal District. Brasilia.

[17] Réquia Jr., W.J., Roig, H.L. and Koutrakis, P. (2015) A Spatial Multicriteria Model for Determining Air Pollution at Sample Locations. Journal of the Air \& Waste Management Association, 65, 232-243.

[18] Réquia Jr., W.J. and Roig, H.L. (2014) Multi-Criteria Model in Geographic Information Systems for Determination of Sampling Points of Air Pollution. Urban Environmental Pollution. Climate Change and Urban Environment-Conference, 45-46.

[19] Aguiar, E.F.K. and Roig. H.L. (2014) Air Pollution Dispersion Mapping by Remote Sensing: Case Study from the Federal District. GEO Processing 2014: The Sixth International Conference on Advanced Geographic Information Systems, Applications, and Services, Barcelona, 15-23.

[20] Rada, E., Ragazzi, M., Brini, M., Marmo, L., Zambelli, P., Chelodi, M. and Ciolli, M. (2012) Perspectives of Low-Cost Sensors Adoption for Air Quality Monitoring. UPB Scientific Bulletin, Series D, 74, 241-250.

[21] E2V (2010) e2v Metal Oxide Semiconductor (MOS) Gas Sensor Evaluation Kit. User Guide, Vol. 44, United States of America, 1-29.

[22] Figaro Engineering Inc. (2014) Gas Test Box SR\#3. Japan.

[23] NIST. National Institute of Standards and Technology (2011) Chemistry WebBook. U.S. Secretary of Commerce on Behalf of the United States of America, Gaithersburg.

[24] Beychok, M. (2005) Fundamentals of Stack Gas Dispersion. 4th Edition, California.

[25] ESRI (Environmental Systems Resource Institute) (2014) ArcInfo 10.2.2. ESRI, Redlands.

[26] Yamauti, M. (2013) Simple Linear Regression in Statistical Textbooks for Courses of Administration: A Didactic Study. PUCSP, São Paulo.

[27] Loreto, V. (2012) Report on: Sensor Selection, Calibration and Testing. Enhance Environmental Awareness through Social Information Technologies, Italy, 1-73.

[28] Li, X., Ramasamy, R. and Dutta, P. (2009) Study of the Resistance Behavior of Anatase and Rutile Thick Films towards Carbon Monoxide and Oxygen at High Temperatures and Possibilities for Sensing Applications. Sensors and Actuators B: Chemical, 143, 308-315.

[29] Yoo, K.S. (2011) Gas Sensors for Monitoring Air Pollution. Department of Materials Science and Engineering, University of Seoul, Seoul. 
Scientific Research Publishing (SCIRP) is one of the largest Open Access journal publishers. It is currently publishing more than 200 open access, online, peer-reviewed journals covering a wide range of academic disciplines. SCIRP serves the worldwide academic communities and contributes to the progress and application of science with its publication.

Other selected journals from SCIRP are listed as below. Submit your manuscript to us via either submit@scirp.org or Online Submission Portal.
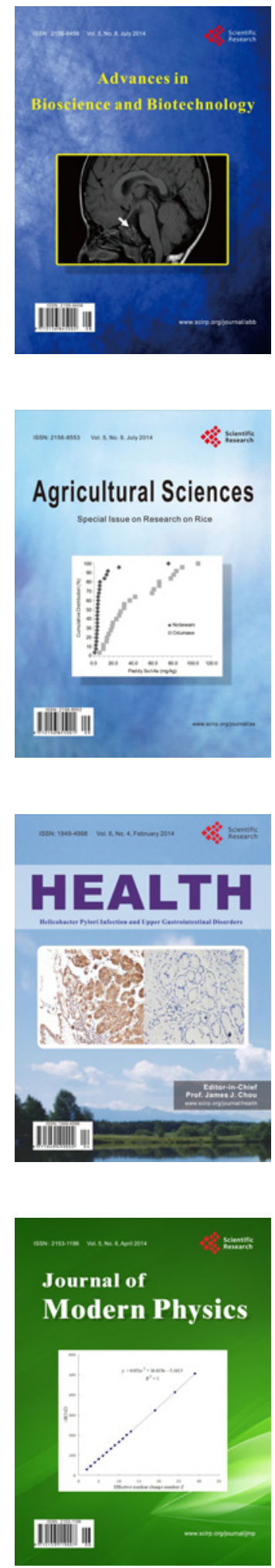
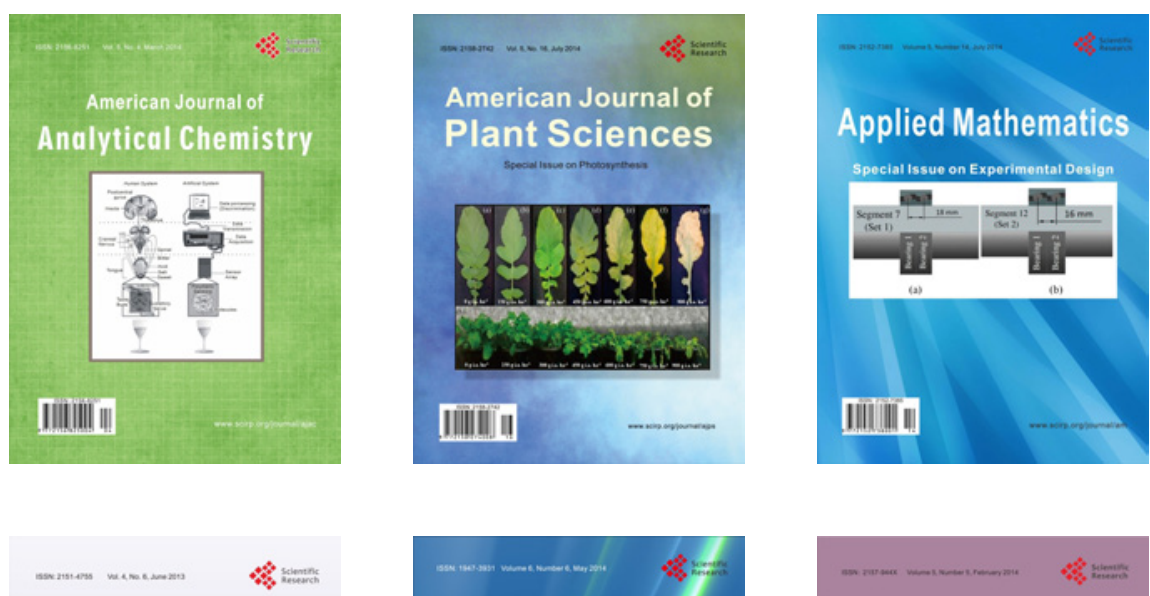

Creative Education
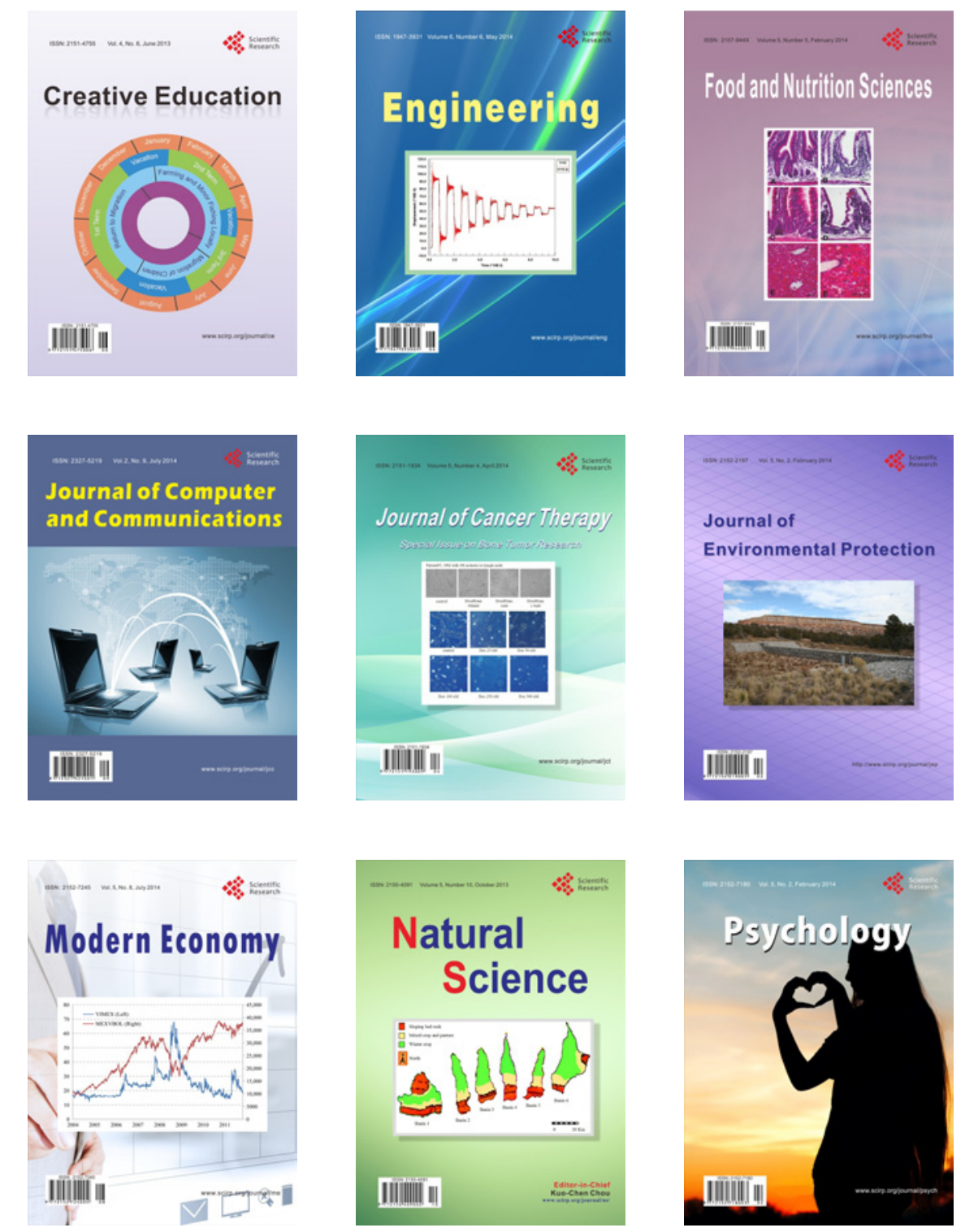